\title{
Critical Media Literacy as a Transformative Pedagogy
}

\author{
Lorayne Robertson, Joli Scheidler-Benns \\ Faculty of Education, University of Ontario Institute of Technology \\ Oshawa, ON, Canada
}

\begin{abstract}
Critical media literacy is important because media's ubiquitous presence has become the digital wallpaper of life, and students need to learn how to use media responsibly for learning, communicating, and participating in democratic societies. Media literacy skills have been defined historically in uncritical ways: awareness of the dangers of (over) exposure to media; the study of media as an art form; or learning about the technical elements of media such as audience. The focus of this paper is on deeper, more complex conceptions of media literacy within its complicated social and educational contexts. The authors argue that critical media literacy can provide rich learning for students. Critical media literacy builds skills of analysis and critique in the deconstruction and interpretation phase where students learn to recognize hegemonic aspects of media. Deconstruction is only one side of the critical equation, however. During the media production phase, critical media literacy can give voice to students and empower them to take action to make changes in society. In the process, critical media literacy can lead students to deeper understandings of literacies and discourses in society than previously considered possible. This paper theorizes critical media literacy in both of these phases: its deconstructive, critical phase and its transformative and critical production phase. An analysis is provided also of some of the challenges associated with critical media literacy as a transformative pedagogy.
\end{abstract}

\section{Introduction}

Media messages can change and do change from country to country, but the influence of media is an issue compelling the attention of educators and parents in multiple countries globally. Children and adolescents are influenced by media and popular culture which is presented in the forms of advertising, entertainment media, computer games, and social media, for example. These media messages may be viewed and accepted without being questioned, or they can be viewed with a deeper discernment of the powerful ways that media can cause the positioning of certain groups of people and, as a result, be highly influential.

When media messages are deconstructed and discussed in classrooms and homes where children and adolescents can build critical media skills, they learn about how media operates within society. This paper takes the position that critical media literacy skills can be cultivated to build students' critical awareness of the workings of power and privilege in society and help students understand that they can improve the world through the development of a critical consciousness. Critical media skills can also help students learn how to strengthen their voices for democratic participation in the pursuit of solutions of issues of global importance.

\section{New literacies, new pedagogies}

In the final decade of the 20th century, it was evident to some theorists that digital technology was changing the nature of community, communication, and everyday life, while creating a blend of technology, media, and consumerism which was highly influential when examined through the lens of culture studies [1]. The ubiquity of media's presence in modern society could reasonably be expected to also change education, as education exists in society. Technology was also changing literacy from a finite set of skills taught in school, to seeing literacy instead as multiple, new literacies - new practices which are historically, socially and culturallysituated [2] [4].

At the same time, there was a growing awareness that early canons of literacy and notions of what constituted educated language had privileged some societies and cultures and marginalized others [2]. More critical literacy practices began to emerge, including critical media literacies [17].

The development of critical media studies has multiple origins - only some of which are explored here to illustrate the building of this school of thought. In the United States, members of the Frankfurt School (started by intellectuals who were refugees of fascism) were critical of American media which communicated mass messages of consumer capitalism in the post-World War II era [1]. A second key group in media studies at that time was the Toronto School in Canada which became famous through the work of Marshall McLuhan, who is credited with identifying the shift from print influence to electronic forms of mass media [1]. 


\subsection{A pedagogy of multiliteracies}

At the close of the 20th century, scholars who came to be known as the New London Group (NLG) noted the emergence of new literacies and recognized that media communication should no longer privilege a dominant view or a standard language. Collectively, they theorized a pedagogy of multiliteracies which would build students' literacies in a broader society which included many voices and experiences not previously acknowledged. The NLG theorized that teachers who had immersion and explicit instruction in these new critical literacy practices would transform their teaching practice [2]. To see digital literacies within a global, social context recognizes the complexities of social contexts where different histories, cultures and ideologies are given voice [2], [3], [4].

While the focus of the NLG was on teacher instruction, other aspects of new literacies were emerging which focused on student authorship. These literacies included opportunities to produce, communicate, and disseminate information by anyone with access. Students were both viewers and authors of new media, either through creating original work or by remixing, so concepts such as authorship and audience were also changing [4].

\subsection{Critical pedagogy}

Social consciousness began to emerge on a larger scale during the later portion of the 20th century as suppressed voices began to be heard, increasing the need for critical media skills. In Canada, a new Charter of Rights and Freedoms [5] named the categories of discrimination (such as racism, sexism, homophobia, class prejudice, etc.) which helped Canadians to understand their rights as well as the grounds for claiming discrimination. Canada as a nation is characterized by diversity with more than 200 ethnic origins reported recently [6] and a continual influx of new immigrants. Because Canadian society is characterized by its ethnic, cultural, and religious diversity, Canadian curriculum studies and pedagogies require recognition of pluralized ways of knowing. One means of making this shift is through critical pedagogy.

Critical pedagogy builds a bridge between what is happening in broader society and what is happening in the classroom through its premise that schools are politically-contested spaces [9]. In some classrooms, social issues are left outside the classroom door and a focus is maintained on traditional skills. While some teachers see this as remaining neutral [7] [16], it could be argued that refusing to recognize the consequences of privileging a dominant view is, in itself, a political position. In Canada, this might take the format of a curriculum which ignores national issues of poverty and homelessness. Even the current ways of teaching history can deny the need for reconciliation with indigenous persons and those who have experienced racist policies.

Teachers need to be subject experts but they also need to view schooling within its broader cultural and social contexts [2], [9]. Critical pedagogy approaches in schools question whose knowledge is valued [9], and if it is acceptable to present knowledge to students in unquestioning ways, such as descriptions about war from the point of view of one side of the conflict.

Teachers who practice critical pedagogy skills are more culturally-responsive and understand that there are alternative forms of knowing and experiencing school and life. This has the potential to make education as complicated and complex as real life. For example, in Canada, it is possible to have firstgeneration students from oppositional sides of a global conflict in the same classroom. That same classroom theoretically could include the children of the peacekeepers, as well as those seeking refuge from the conflict. Teachers who acknowledge multiple literacies and histories are also transformed through these diverse situations.

Another key understanding in critical pedagogy is the acknowledgement that schools are not fair to all students and students in marginalized or low-status groups are under-represented in school success. Kincheloe states that this occurs when students "have failed to fit the proper demographic" [9] p. 7. Critical pedagogy encourages students to question and challenge the dynamics of power, privilege, and disadvantage for segments of society relative to their race, gender, class, sexual orientation, ability, body size, membership in indigenous communities, and age, etc. [2], [7], [8], [9].

McIntosh theorizes how curriculum could become more inclusive in stages, beginning with the admission or recognition that traditional schooling has favored a single system of hegemonic values. Gradually, other values and experiences can be built into the curriculum until no single history or interpretation is privileged [3]. This could also be reflected in literacies, where different languages and interpretations of media would be seen as assets not deficits [2], [9]. There has been a recognition that the world's knowledge, when told from different perspectives, is much more complex and rich than was originally thought [2], [9] and is layered with assumptions based on meanings that have not been questioned for some time. The result is that assumptions are made and persist, such as the labelling of students as disabled rather than seeing that every person has degrees of ability, or that the school system needs to be more enabling [10].

Teachers also need to understand how traditional categories construct identities for some students which can stand in the way of their success, such as 
making assumptions about student ability based on their postal code or country of origin [8], [9], [10]. This is particularly harmful when a student's level of participation and engagement is attributed to their category of difference rather than seeking new solutions.

Technology advances can erode some of these earlier binaries. For example, some students who have challenges with reading can now use text-tospeech readers to access grade-level material. Labelling of these students as disabled (traditional category) serves no purpose. The school can enable students' acquisition of literacy through assistive devices and technology (transformative). The category of "other" no longer should matter, because diversity itself is becoming increasingly complex and resists categorization [8], [11]. While earlier categories of difference were used to substantiate social inclusion or exclusion, a critical pedagogy stance acknowledges that diversity is expected but challenges us to consider how schooling can be fair for every student.

\subsection{New teacher-student relationships}

Another key element of critical pedagogy is the change in the roles of teachers and students. The NLG define pedagogy as, "a teaching and learning relationship that creates the potential for building learning conditions leading to full and equitable social participation" [2] p. 60. The roles of teachers and students change when students are encouraged to include their out-of-school literacies into the classroom and to see themselves as designers of their futures [2]. Kincheloe explains that in critical pedagogy approaches teachers do not give up their authority in the classroom but they "assume the mature authority of facilitators of student inquiry and problem-posing" [9]. Critical pedagogy honours students' experiences and knowledge. When it is used in developmentally-appropriate ways, it invites students to be self-directed and produce knowledge [9]. In other words, critical pedagogy's goals are met through encouraging students to be critical thinkers and questioners who can consider the complexity of life's issues with teacher support.

\section{Critical media literacy}

The emergence of new forms of media communication has implications for the learning that happens in schools [2] even though schools may not have fully embraced these implications [4]. For example, while it may have been an accepted understanding that learning takes place in schools, it has been claimed recently that more learning happens through new media and technology (i.e., outside of school) than from teachers in schools and professors [16]. The emergence of new technologies and new literacies opens new vistas to view for pleasure or to receive information in new ways. Technology has also created new audiences for its text and media productions. Students need to learn how to navigate successfully in this world of multiliteracies [2] and teachers and schools need to remain relevant [16].

Students need guidance as they explore new media which may, even though they are current, reproduce assumptions which have become normative. Critical media literacy helps students to interrogate these hegemonic dimensions. Ideally, studies to incorporate, interrogate, and produce new media need to be explored in the context of classrooms with teacher support and in homes with caregiver support.

Critical media literacy is seen as one way to link in-school literacies to out-of-school literacies, in what Alvermann and Hagood term as "troubling the binaries of established school discourse" (such as traditional literature versus popular literature or inschool versus out-of-school learning) [12]. They see that linking school to the media and discourses of the outside world can help students question the workings of injustice, inequality, and relations of power (such as gendered identities). Alvermann and Hagood's definition of critical media literacy includes three components: enjoying media; exercising choice in media selections; and producing personal, individual media texts [12]. These critical media literacy skills do not position the viewer as passive, but instead encourage the understanding that different individuals view or understand the same media differently. It follows then that the concepts of audience and perspective are important in order to author for different audiences and to appreciate that there will be different interpretations.

Media are not neutral in critical media literacy studies, as media texts can reproduce power relations or challenge them. Alvermann and Hagood state, "[W]e are interested in the pedagogical implications of helping students experience the pleasures of popular culture while simultaneously uncovering the codes and practices that work to silence or disempower them as readers, viewers, and learners in general" [12].

Tisdell examines the positive and negative influences of media in the lives of adults, noting for example, that the presence of overly-thin actresses can make women question their own body image, and anti-aging product advertising can make the inevitable act of one's aging seem less than socially acceptable. She documents the impact of critical media literacy as a transformative pedagogy in the higher education setting while working with adults and makes the key point that exposure to the media, supported by discussion in the class setting, can help adults transform their views [15]. 
The impact of media is not restricted to adults, however. Kellner and Share call the media a "powerful public pedagogy" which is "frequently invisible" and "is absorbed unconsciously" [17]. They make a compelling case for the inclusion of critical media literacy in every year of schooling, calling it a 21 st century transformative pedagogy.

Kellner and Share propose that critical media literacy should not only challenge the politics of representation of dimensions such as gender, race, and class (and others), but it should critique mainstream approaches to the teaching of literacy in order to bring about social change. In their view, students should be encouraged to use media and communication technologies to produce alternative, counter-hegemonic media [17].

Although a need for critical media literacy has been established by multiple scholars [2], [4], [7], [8], [12], [17], concerns have been raised that schools are not meeting this mandate [8] [17]. For example, Alvermann and Hagood conclude that the discourse in American schools at the turn of the century would indicate that schools were "illequipped" to support critical media literacy because they have not begun to recognize out-of-school learning from media [12].

\section{Transformative pedagogy}

Both access to information and access to the tools of media production have changed in exponential ways for students in the present era. Understanding the grammars of the world has become a necessity to prepare students for life in the working world and active citizenship [2]. Media and culture help to shape student identities and help them see where they belong in local, national, and global society.

New technologies have changed the concept of audience to a global audience, and they allow students to become authors of complex, sophisticated media productions using software that is readily available for them to download. Despite these advances in technologies, researchers claim that there is little evidence that media has been viewed as a tool for transformative learning and there is a shortage of literature which connects critical media literacy to transformative pedagogy [15].

Curry-Stevens theorizes that the recognition and subsequent dismantling of some of these traditional categories, norms, and canons of schooling cannot be dictated to individuals, and in particular, teachers, because learning about privilege involves personal learning [13]. As Cranton outlines, this type of change comes about through reflection and cognitive dissonance when a person's world view is challenged [14]. These types of changes for teachers can be encouraged through awareness, education, and policy. The process of transformative learning has generally been situated in the literature about adult learning, where elements of transformative thought include cognitive dissonance and reflection. We propose that these outcomes can be realized through critical media studies.

As Cranton [14] reminds us, the process of transformative learning takes place incrementally and in small steps for most people. She defines transformative learning in the following way:

Transformative learning occurs when a person, group, or larger social unit encounters a perspective that is at odds with the prevailing perspective. The discrepant perspective can be ignored or it can lead to an examination of previously held beliefs, values, and assumptions. When the latter is the case, the potential for transformative learning exists, though it is not called transformative until there is a deep shift in perspective and noticeable changes in actions as a result of the shift [14].

We ask whether or not a student's shift from seeing herself in media's mirror to seeing herself as a producer of counter-hegemonic messages represents a transformative step for a learner. If so, then critical media literacy could be considered a transformative form of pedagogy for all learners, including adults.

According to Kellner, media culture is a form of cultural pedagogy. He describes it this way:

Media are forms of pedagogy that teach people how to be men and women. They show how to dress, look, and consume; how to perceive and react to members of different social groups; and how to be popular and successful, as well as how to avoid failure. [21.

In order for students to understand that the media is not their mirror, they need to see that media messages have been constructed and shaped and that they themselves, as an audience, have been positioned through this media construction [17]. Students need to acknowledge also that media can present messages as if they are reality (one good example of that is the pretext of the urgency of "breaking news" which may or may not be news of any particular significance). Students may also mistakenly believe that the media is just entertainment, but in fact, the messages can be quite problematic and need to be explored [17].

It is similarly problematic in a digital era, however, for students to be passive learners who are dependent on the teacher or media/ technology as the major source of information. As schools re-think traditional hierarchies and troubling dichotomies (such as gender binaries, and the ability/disability binary as examples) so, too, schools need to encourage students to become independent critical thinkers. One of the ways to support this 
transformative type of pedagogy is through a framework of key messages and questions.

\subsection{Critical media literacy framework}

This framework helps teachers and students pursue critical media literacy by guiding their media critique and reconstruction. It is a series of key messages and questions which needs to be accompanied by developmentally-appropriate texts/media which may be selected by the teacher or the students but would be vetted through the teacher. We propose this framework as a starting point and invite other scholars and practitioners to build on and improve this framework, which is designed to support transformative learning in critical media studies.

1. All media messages are built or constructed to show us a version of reality (narrow, limited). Questions: What version of reality does this commercial or media message show? Is this your reality? How does this compare to your reality? What do you want to say about this?

2. Media messages are constructed to persuade the audience toward a certain result. Most messages are profit or power driven. Questions: What is the goal of the media maker? Is it for profit or power? How do you know? What is your response to this?

3. Media messages are not neutral. They have values and a point of view and they promote an agenda. Question: What values and point of view are presented through this media message? Whose values and point of view are missing? How do you want to respond to this media message?

4. Media can be designed to appeal to only some people or to different audiences in different ways. Questions: For whom do you think this media message was created? What makes you think this? How might another (gender, culture, ability group, sexuality group) see this media message? What would be the response of another group to this media message? What would be your response?

5. Media messages show stereotypes or make fun of stereotypes. Usually, stereotypes are harmful. Questions: How are stereotypes present or absent in the media message? Does the definition of this category or the characteristics in the media for this category of people match your understandings of individuals in this group? How would you like to change this through a media response? What would you create to change the message?

6. As a media critic, you can take apart, interrupt, and replace messages with positive, empowering messages. Questions: How could you interrupt this message or replace it? What could you do, say, or create? What could you create or say to make a more positive or empowering message?

According to the New London Group [2], new pedagogical elements such as technology and the acknowledgement of different perspectives will help to transform education, which they term the "how" of a new pedagogy of multiliteracies. Teachers are seen as the designers of the learning environments; engaging students in meaningful learning experiences which build on students' previous learning (situated practice). The teachers introduce students to the metalanguage of media analysis where they help students grow in their understanding with support (overt instruction). Teachers help students relate their learning to what is happening historically, socially, culturally, or politically (critical framing) and then students and teachers undertake new practices based on new understandings and values (transformed practice) [2].

Although Breuing [20] finds that most selfproclaimed critical pedagogues identify with the constructivist paradigm, we argue that the connectivist paradigm [19] is more useful for understanding critical media literacy. The landscape of today's media is constantly changing and students need to learn how to interpret the messages in the midst of chaos. She asserts that constructivist approaches lack the social justice impact, missing the empowerment angle of student-generated content implied in critical levels of learning. She finds also that these same teachers rarely mention the purpose of critical pedagogy as a means for emancipation or empowerment. Rather, the approach remains studentcentered and as a means of practising democracy. The challenge here is that there are many simultaneous world events taking place and shaping the future for our students and these same students may not be aware of all of them. Students cannot always build on their own existing experiences as implied by the constructivist paradigm; they must be taught to search outside themselves also [20].

The critical media literacy framework of key messages and questions which has been presented here aligns with a multiliteracies pedagogy [2]. It engages students in the deconstruction of media literacy texts which are part of their world (situated practice). Through the key messages and the questions, teachers work with students to ask questions about the media messages using a metalanguage about media literacy forms, points of view, and audiences (overt instruction). In the process, students are encouraged to interrogate the layers of meaning in the media text (critical framing). Throughout the application of this framework, students and teachers gain new understandings and construct new media to demonstrate and 
communicate their understandings (transformed practice) [2].

Critical media literacy as a transformative pedagogy then, requires more than critical pedagogy or raising critical consciousness of the inequities in society which the media may be replicating. It requires a deep understanding of how media messages are being received as well as how those messages have been constructed. The source of the media messages may or may not be in mainstream culture. In order for teachers to fully understand the impact of media on students' thinking and identity formation, they need to have some insights into the digital world of their students and this includes the media in the students' out-of-school lives. Through these shared dialogues, the teacher's learning is also transformative.

For critical media literacy to flourish in classrooms, teachers need to become nonjudgemental co-learners along with their students. The dimensions of the classroom may have to change so that teachers become willing to learn from students who may be more experienced in out-ofschool digital literacies. This same non-judgemental approach needs to be taken with various perspectives and experiences in the lives of students that may be completely foreign to the teacher.

Attempts to bridge the gap between home life and school life help students and teachers relate to their world in authentic ways. Teachers continue to select developmentally-appropriate and culturally-relevant learning materials. Within the safety of the classroom atmosphere and with the guidance of the teacher, dialogue takes place between students and their peers, and between students and teacher, which helps both students and teachers understand media messages more deeply. The organic quality of this relationship means that the "end" product or "outcome" may change as a result of the dialogue. Typical curriculum learning strands become the starting point, rather than the end point, and add foundational structure to the chaos.

When engaged in this type of dialogue, students gain new understandings of how students in minority positions socially and globally are experiencing life and the impact of media. They can reflect, in turn, how students in dominant groups are experiencing life and media. Each student is given a voice and receives credibility for their own experience and interpretation of the media. Take for example, the following scenario.

A class of 12-year-old students is having difficulty making connections to what they are reading and their own lives (text to self). They are also experiencing challenges connecting their reading to what is happening globally (text to world). Working with their teacher, they locate different sources of media which tell the stories of refugee families seeking asylum. Through a process of guided inquiry, during which the teacher helps them identify how media stories are positioned for specific audiences, the teacher helps students explore the issues for the persons within and outside the centers of global conflict and how the media is positioning this information.

One of the students tells her own story of immigration from her country of origin, including the sadness at the loss of relatives and the joy of acceptance in a country which is at peace. This adds richness to the students' exploration of the issue. In this process, students deepen their understanding of the issues, but also build their critical literacy and digital literacy skills. When they feel that they have an understanding of the issues, students create and share media to demonstrate their understandings of a current and significant world event. Again, with the guidance of their teacher, they compare their media representations with the reports in the media, leading them to further insights.

As this example illustrates, critical media studies are what Kellner and Share have termed, "a powerful starting place for problem-posing transformative education" [17]. Students begin to appreciate the complexities of real life. They see that among their peers there are multiple perspectives and different lifeworlds of experience which are seen as assets and not deficits [2], [10].

\section{Conclusion and recommendations}

In proposing that schools and school curricula take up more critical forms of media literacy, we are not suggesting that there is not value in other forms of media literacy. For example, it is still important to consider how much time is spent watching violent media and the implications of over-exposure to violence for young children and adolescents. Kellner and Share [19] have termed this approach to media literacy the protectionist approach. There is also value in appreciating the qualities of media and using media in creative ways for self-expression which they have termed the media arts approach. The predominant curricular approach to media literacy in the educational jurisdiction with which we are the most familiar relies almost exclusively [8] on what Kellner and Share would term the media literacy curricular approach. In this approach, students examine how to access and analyze multiple forms of media, including current media culture. The stance of the educators working with this type of approach has been described as politically neutral [18]. 
All of these approaches to media literacy are about learning, but none of them offer the depth of understanding and connection to students' lifeworlds as the study of critical media literacy. Being an increasingly global society, it is becoming more important for students to understand what is going on because the impact of events is experienced globally.

As educators, we need to consider the costs of uncritical media education. What is the cost to society if the one-sided positions in text and in media are unquestioned? What is the cost to the validation of multiple persons' experiences if singledimension renditions of history are the only accepted canon? What are the costs of single-sourced news and entertainment or media control by political, economic, or corporate interests?

Because some of the current media have aspects of hegemonic, mono-cultural control, we can already begin to speculate the costs to society if students are not allowed to interrogate media texts through more critical and analytic lenses. Already, many young people are creating alternate texts and media in their out-of-school lives. Guiding students to deepen their engagement with their creations can give them power in their worlds. The time for teachers and schools to engage students in discussions about real change in today's classrooms has already arrived. In the spirit of connectivism [19], we encourage others to join into this dialogue.

\section{References}

[1] Hammer, R., Kellner, D., (2009). Media/cultural studies: Critical approaches. Peter Lang.

[2] New London Group, (1996). A Pedagogy of Multiliteracies: Designing Social Futures. Harvard Educational Review, 66(1), 60-92.

[3] Mcintosh, P., (1989). Curricular re-vision: The new knowledge for a new age. Educating the majority, 400412 .

[4] Jewitt, C., (2008). Multimodality and literacy in school classrooms. Review of research in education, 32, February, 2008, 241-267.

[5] Canadian Charter of Rights and Freedoms, s 2, Part I of the Constitution Act, 1982, being Schedule B to the Canada Act 1982 (UK), 1982, c 11.

[6] Statistics Canada, (2013). Immigration and Ethnocultural Diversity in Canada. Retrieved @ http://www12.statcan.gc.ca/nhs-enm/2011/as-sa/99-010x/99-010-x2011001-eng.cfm

[7] Robertson, L., Hughes, J. (2011).Investigating preservice teachers' grasp of critical media literacy. Language and Literacy. 13(2) Special Issue, 201, 37-53.
[8] Robertson, L., Doyle-Jones, C., (2015). Pedagogies of difference: Equity and diversity in early childhood policy in Ontario. The International Journal of Holistic Early Learning and Development, 2, 64-76.

[9] Kincheloe, J. L., (2008). Critical pedagogy primer. New York: Peter Lang.

[10] Kalantzis, M., Cope, B., (2012). New learning: Elements of a science of education. Cambridge: Cambridge University Press.

[11] Thompson, D., Robertson, L., (2014). Fit for what? Critical analysis of the Canadian physical education curriculum. Critical Education, 5(19), 1-19. ISSN 19204125 .

[12] Alvermann, D., Hagood, M., (2000). Critical media literacy: Research, theory, and practice in "new times.” Journal of Educational Research, 93, 193-205.

[13] Curry-Stevens, A. (2007). New forms of transformative education: Pedagogy for the privileged. Journal of Transformative Education, 5(33).

[14] Cranton, P., (2010). Transformative learning in an online environment. International Journal of Adult Vocational Education and Technology, 1(2),1-9, AprilJune, 2010

[15] Tisdell, E. J., (2008). Critical media literacy and transformative learning drawing on pop culture and entertainment media in teaching for diversity in adult higher education. Journal of transformative education, 6(1), 48-67.

[16] Macedo, D., (2007). Deconstructing the corporate media/government nexus. In D. Macedo \& S. Steinberg (Eds.) Media literacy: A reader. New York: Peter Lang.

[17] Kellner, D., Share, J., (2007). Critical media literacy, democracy, and the reconstruction of Education. In Macedo, D., \& Steinberg, S. R. (Eds.), Media Literacy: A Reader (pp. 3-23). New York: Peter Lang.

[18] Kellner, D., \& Share, J., (2007). Critical media literacy is not an option. Learning Inquiry, 1(1), 59-69. [19] Siemens, G. (2014). Connectivism: A learning theory for the digital age.

[20] Breuing, M., (2011). Problematizing critical pedagogy. The International Journal of Critical Pedagogy, 3(3).

[21] Kellner, D., (2011). Toward a critical media cultural studies. In R. Hammer \& D. Kellner (Eds.) Media/Cultural Studies: Critical approaches. pp 5-24. New York: Peter Lang. 